\title{
Momentos do parque em uma rotina de educação infantil: corpo, consumo, barbárie*
}

\author{
Ana Cristina Richter \\ Universidade Federal do Paraná \\ Alexandre Fernandez Vaz \\ Universidade Federal de Santa Catarina
}

Correspondência: Ana Cristina Richter Rua Dom João Becker, 641, apto 305 88058-600- Florianópolis-SC E-mail: ana_tinaa@uol.com.br

\footnotetext{
* 0 artigo é resultado parcial do programa de pesquisa Teoria Crítica, Racionalidades e Educação II, financiado pelo CNPq.
}

\section{Resumo}

0 trabalho resulta de uma pesquisa de abordagem etnográfica realizada em uma creche da Rede Pública de Ensino de Florianópolis (SC). Os dados foram analisados considerando-se o "tempo didático" - recomendado pela legislação -, estruturado por uma rotina constituída por diferentes momentos: entrada, higiene, alimentação, sono, parque, atividade orientada, saída. Inspirado por tópicas da Teoria Crítica da Sociedade, o texto aborda os momentos de parque, declarados como "ocasiões privilegiadas de educação", tanto nos discursos das professoras, quanto nas ações que distinguem esses momentos dos demais, estabelecendo uma certa contraposição entre "tempo de trabalho" e "tempo livre”. Nessa relação, além de configurarem-se como períodos de renovação das energias para as demais atividades, esses momentos acabam por escusar um acompanhamento mais atento por parte dos professores: o olhar adulto "precisará" apenas afastar as crianças de locais inconvenientes ou evitar feridas "expostas", conformando um conjunto de práticas sociossanitárias centradas nas necessidades vitais e que contribuem na eliminação de desvios e diferenças, na garantia de pseudogratificações. A ausência de uma aproximação mais atenta também colocará as crianças entregues a uma ambígua "espontaneidade", sujeitas à violência que acaba por produzir cicatrizes que se colocam, principalmente, sobre o corpo, fomentando uma educação que, ao invés de se contrapor à barbárie, a privilegia. Os resultados revelam ainda a presença de produtos para o consumo do lazer que informam, de antemão, a sequência de operações a reproduzir, exigindo gestos e ações automatizadas que preceituam a aridez da imaginação.

\section{Palavras-chave}

Educação infantil - Educação do corpo - Tempo livre - Teoria crítica da sociedade. 


\title{
Playground moments in an early childhood education routine: body, consumption and barbarism*
}

\author{
Ana Cristina Richter \\ Universidade Federal do Paraná \\ Alexandre Fernandez Vaz \\ Universidade Federal de Santa Catarina
}

Contact:

Ana Cristina Richter

Rua Dom João Becker, 641, apto 305

88058-600- Florianópolis-SC

E-mail: ana_tinaa@uol.com.br

* This article is a partial result of the research program on Critical Theory, Rationalities and Education II sponsored by CNPq.

\begin{abstract}
The work results from an ethnographic research carried out in a daycare center of the public school system of Florianópolis (SC). The data were analyzed considering the "didactic time" - recommended by the legislation -, structured in a routine comprising various moments: arrival, cleaning, feeding, sleep, playground, guided activity, departure. Inspired by issues from the Critical Theory of Society, the present text deals with the playground moments, considered as "privileged situations for education", both in the teachers' discourses and in the actions that distinguish these moments from the others, establishing a kind of opposition between "work time" and "free time". In such relation, apart from being regarded as periods to renew energies for the other activities, these moments offer an excuse to suspend the closer following up of activities by the teachers: the look of the grown up "will need" only to steer children clear of inadequate places or to avoid "exposed" wounds, shaping a group of sociosanitary practices around the vital needs, and that contribute to eliminate deviances and differences in pursuit of pseudogratifications. The absence of a more careful approximation will also leave children to an ambiguous "spontaneity", subjected to the violence that produces scars, mainly on the body, and which promote the kind of education that privileges barbarism instead of opposing it. The results show also the presence of products for the consumption of leisure that inform beforehand the sequence of operations to be reproduced, requiring automated gestures and actions that stimulate the barrenness of imagination.
\end{abstract}

\section{Keywords}

Early childhood education - Body education - Free time - Critical theory of society. 
São 15 h e 12 minutos. Na sala, a professora termina de recolher os blocos de desenho, auxilia quatorze crianças a dobrarem seus casacos e guardá-los em suas mochilas. A tarde está ensolarada, a temperatura amena e os pequenos são conduzidos ao pátio da creche para junto de trinta outras crianças entre três e seis anos de idade, e seis adultos, tal como ocorre diariamente, pela manhã, e também à tarde, por períodos que variam entre cinquenta e oitenta minutos. Inicia-se, assim, um “novo" Momento de Parque.

0 fragmento acima reúne trechos de um diário de campo relacionados à passagem de um momento ao outro da rotina de uma creche da Rede Pública de Ensino de Florianópolis na qual realizamos um estudo de abordagem etnográfica. 0 objetivo da pesquisa consistiu em traçar uma agenda de estudos sobre a educação do corpo em ambientes educacionais para a infância, abordando um conjunto de momentos que compõem a rotina institucional. Partindo da consideração em torno da qual a visibilidade do corpo no contemporâneo aparece, se refaz e se reforça de modo particular também nos ambientes educacionais, contribuindo na (con) formação de comportamentos e subjetividades, ocupamo-nos naquele momento de dispositivos pedagógicos que transpassam o corpo, observando os modos como operam e se organizam no espaço-tempo da instituição. Esses momentos são, portanto, corporais.

Além de entrevistas com atores institucionais e familiares de crianças e uma análise documental, realizamos um longo período de observação, relatado nas mais de quatrocentas páginas do nosso diário de campo. Os dados foram analisados considerando-se o chamado "tempo didático" - recomendado pelos Referenciais Curriculares Nacionais para Educação Infantil -, estruturado, como dissemos, por uma rotina que envolve os cuidados, as brincadeiras e as situações de aprendizagem orientada, constituída por diferentes momentos: entrada, higiene, alimentação, sono, parque, atividade orientada e saída.
Revisitando os resultados da pesquisa, atemonos, neste texto, aos momentos de parque. Os pressupostos desses momentos são organizados institucionalmente pelos supracitados referenciais e, no plano local, pelo projeto políticopedagógico da instituição investigada, envolvendo, juntamente com os demais períodos que compõem a rotina, ações sistematizadas, experiências e situações planejadas com o intuito de favorecer o desenvolvimento das capacidades de apropriação e conhecimento, ambas vistas como potencialidades da criança.

Apesar de esses períodos de parque aparecerem declarados como "ocasiões privilegiadas de educação", tanto os discursos dos professores quanto as suas ações distinguem esses momentos dos demais, estabelecendo uma espécie de contraposição entre "tempo de trabalho" e "tempo livre”. Nessa relação, conforme argumentaremos ao longo deste texto, os momentos de parque, além de se configurarem como períodos de renovação das energias para as demais atividades, acabam por dispensar a exigência de um acompanhamento mais cauteloso por parte dos professores presentes no local. Nesses termos, o olhar adulto poderá apenas, como veremos mais adiante, afastar as crianças de locais inconvenientes ou evitar feridas "expostas". A ausência de uma aproximação mais cuidadosa acabará por deixar as crianças entregues à ambiguidade do "espontâneo", expostas ao risco da violência que se materializa e permanece em marcas que se colocam, principalmente, sobre o corpo.

0 texto está estruturado de forma a apresentar brevemente o campo de pesquisa e, mais detalhadamente, a arquitetura do parque na forma dos recursos ali dispostos, determinantes no modo e na forma de ocupação e nas relações que se estabelecem naquele território. $\mathrm{Na}$ segunda parte elaboramos algumas observações a respeito do tempo de parque, caracterizado pelos profissionais da instituição como um tempo livre, e sobre as implicações daí decorrentes. $\mathrm{Na}$ terceira parte, procuramos observar a constituição do olhar dirigido às crianças nos momentos 
de parque, considerando sentidos e significados a ele subjacentes. Por fim, elaboramos breves notas finais enfocando alguns elementos que pesam sobre a questão do momento de parque tomado como tempo "livre".

\section{Considerações sobre a arquitetura do parque: disciplina e controle}

Vinte e seis professoras de sala e auxiliares, além de duas professoras de educação física, diretora, supervisora, merendeiras e serventes, atendem cento e oitenta crianças, agrupadas por faixa etária, em um ambiente composto por oito salas, cozinha, refeitório, banheiros, sala de estudos e de coordenação, ocupando $551 \mathrm{~m}^{2}$ de área construída. A creche dispõe de um terreno para horta, um pequeno pátio junto ao portão de entrada e dois parques. Ao lado direito do prédio principal está o parque "dos maiores"1, ocupando grande parte da área lateral. 0 muro amarelado, cuja pintura se encontra em condições precárias, recebeu grades - insistentemente solicitadas - a fim de evitar a fuga das crianças e garantir a segurança da creche contra "invasões de pessoas estranhas", conforme nos disse uma profissional da equipe diretiva.

Uma pequena porção do terreno é coberta por grama e o restante é composto de solo arenoso. Fixos sobre o solo há quatro brinquedos industrializados de madeira, uma casinha, dois escorregadores, um trepa-trepa, um gira-gira quebrado, todos com armação de ferro. Uma outra estrutura, que abrigava balanços, ainda se encontra no parque, embora esses, em condições precárias, já tenham sido retirados. Nesse espaço, as crianças encontram modos diversos de se movimentar, pendurar, balançar, sentar, escorregar. Além desses recursos, uma caixa de madeira onde foram depositados brinquedos elaborados em sua maioria com material de sucata, algo nem sempre visto como ideal pelas profissionais da instituição, também se coloca à disposição dos pequenos.

Com relação ao terreno que abriga o parque e aos recursos ali dispostos, destacamos dois aspectos observados no campo e nas vozes das professoras. 0 primeiro diz respeito ao que as últimas denominam "comportamento das crianças no espaço da rua”, por circunstância da má conservação dos materiais e também pelas dificuldades encontradas para "controlar os pequenos”, que seriam "muito agitados".

Se o projeto político-pedagógico da instituição aponta a constituição do ambiente como "um dos eixos primordiais do trabalho com as crianças”, uma vez que contribuiria significativamente para estimulação de "experiências de aprendizagem e de relacionamento”, este aspecto não corresponde, na visão das professoras, ao parque da creche. As profissionais apresentam queixas quanto à organização, o estado de conservação e aos materiais disponíveis, como se pode observar na fala de uma professora:

Eu acho que são poucos brinquedos e estragados. Deveria ter outras opções. Eu sinto assim que o parque fica muito violento. Aquela coisa que eles correm até lá embaixo. Aí de uma pedra eles fazem um brinquedo. [...] Tu perde aquele controle. [...] Nós temos uma casinha, mas não tem brinquedo. Qual é o atrativo? 0 atrativo é trancar a porta e eles ficam lá dentro. Ou eles se beijam, ou eles tiram a roupa, ou eles machucam alguém. 0 esconderijo deles é na casinha. Se tivesse brinquedo, seria utilizada de outra maneira.

Essas e outras falas das professoras, tais como "a casinha deveria ser trancada à chave" ou "a casinha me deixa mais velha” - afirmação que quer dizer, no contexto em que foi proferida, que causa fadiga emocional -, parecem extrapolar as críticas de "ordem espacial" ou de "disponibilidade e qualidade de recursos”. Essas colocações e a permanente preocupação com a presença de grades, cercamentos, fronteiras, demarcações daqueles espaços que possibilitam "perder o controle", lembram as sugestões de Horkheimer e Adorno (1985) concernentes à prática pedagógica como

1. Há um outro espaço, destinado àqueles com idade inferior a três anos, denominado de parque dos "menores". 
movimento que pretende eliminar a natureza disforme, em função da aversão aos descontroles, aos desejos desmedidos, à irracionalidade, à inferioridade biológica reconhecida nos animais, nas crianças, nas mulheres, nos loucos, nas criaturas que se supõe serem mais próximas à natureza, mais miméticas (Vaz, 2004). Face ao pavor perante o retorno ao primitivo, àquilo que renunciamos, ao que, de forma obscurecida, expressa a natureza - o não racional -, imprime-se todo um esforço em moldar posturas que contribuem para "produzir" condutas muitas vezes apenas adaptativas. É com esse fim, segundo Horkheimer e Adorno (1985), que se instaura "toda uma pedagogia que desacostuma as crianças a serem infantis" (p. 169) e que exige um enrijecimento contra si mesmo, ou uma mimese a serviço da autoconservação. Trata-se, nos termos dos autores, de converter essa ameaçadora capacidade (mimética) de (re)conhecimento e aproximação não convencional aos objetos, em manipulação organizada da mimese, de acordo com modelos exteriormente determinados.

Os contatos, as expressões não manipuladas, os gestos e comportamentos "inconvenientes" das crianças, tudo o que diz respeito a uma "natureza" não totalmente dominada, tornam-se alvo de contenção, tal como se vê na cena em que "uma criança entra na caixa de madeira onde são guardados os brinquedos de sucata dizendo que irá 'embora em seu barco' e é flagrada pela professora que diz: 'Não é para entrar aí, vai estragar a caixa!'”. Ou ainda, quando acompanhados da professora de educação física ${ }^{2}$, no terreno ao fundo da creche, "oito garotos gritam quando as rajadas de vento se intensificam. E contam: 'Um furacão veio aqui'. E sacodem os galhos 'contribuindo' com o vento. [...] A professora olha para a árvore e avisa em alto tom: "Olha, não é para chacoalhar a árvore'”. Aquela capacidade ameaçadora de assimilação, de mistura, de diluição, de abandono, de desperdício - que os pequenos ainda expressam - deve ser anulada. É preciso que os comportamentos miméticos, que apresentam algo de incontrolável, sejam abandonados, para que o controle da natureza se concretize. Noutros termos, instaura-se um projeto político e pedagógico que se vê capaz de moldar e asseverar hábitos, crenças, valores, por meio de processos operacionalizados que procuram dominar e controlar tanto a natureza externa quanto interna (o corpo, as pulsões), reprimindo tudo aquilo que de alguma forma se mostra desviante da racionalidade instrumental.

Contribui para esse fim um ambiente planejado e preparado para abrigar crianças de acordo com a faixa etária, demarcado por cercas, mobiliário, equipamentos, tal como se estrutura uma sala de aula. Conta-se com a presença das crianças no parque em horários definidos, que podem ser negados aos pequenos como ameaça ou castigo que se concretiza caso "boas condutas" não sejam retomadas. Nesse quadro, podemos dizer que, embora considerado como espaço de criação e liberdade, o parque se coloca como extensão da sala e como estratégia de intervenção para promover a saúde mental e física, sendo os brinquedos determinados por suas funções educativas, classificados com relação à faixa etária, pela função que exercem no desenvolvimento da criança, por sua utilidade pedagógica, além de determinar as formas e possibilidades de realizar os movimentos.

Os brinquedos presentes no parque ainda sugerem distanciamento, visto que sua estrutura não suporta gestos e deslocamentos senão aqueles favoráveis à estatura da infância: o material contribui para desobrigar determinadas formas de aproximação entre adultos e crianças, uma vez que apenas requer o olhar distanciado daqueles que acompanham os pequenos nos momentos de parque. Nesse sentido, os brinquedos que favorecem a socialização entre as crianças acabam também por colaborar para subtraílas das relações com os maiores, aspecto que merece maior atenção quando tratamos de um ambiente educacional, ou seja, de um espaçotempo de relações pedagógicas intencionais,

2. A Rede Municipal de Ensino da localidade conta, desde 1982, com professores (geralmente professoras) de educação física que atuam na educação infantil. 
estabelecidas, necessariamente, na relação entre adultos e crianças.

Ainda no contexto da estrutura do espaço, observa-se que os brinquedos pedagógicos presentes nos parques da creche não se diferem daqueles produzidos, distribuídos e "consumidos" nos parques públicos, nos condomínios residenciais, nos hotéis, em restaurantes. Centenas de empresas de diversão, design e entretenimento divulgam esses produtos, relacionando-os às suas inúmeras "vantagens educativas", entre as quais frequentemente se destacam a "socialização" e a "interação" entre crianças.

Materiais, recursos e ocupações delimitadas para o tempo livre, preocupação com o descanso e o cansaço, ludicidade, diversão, fundam-se numa normalização, num esquema que, silenciosamente, coloca limites, instaura a lei e exige subordinação a técnicas e normas não pela privação, mas pelo controle, acessando tanto o corpo quanto penetrando na constituição da população ${ }^{3}$. 0 momento inscreve-se, então, num contexto mais amplo, em que o corpo aparece como protagonista de processos de controle, sustentados por conhecimentos que se apoiam na hipervalorização da vida biológica, deixando-a "mais sadia”.

\section{Momentos de parque ou tempo livre}

Numa época de integração social sem precedentes, fica difícil estabelecer, de forma geral, o que resta nas pessoas, além do determinado pelas funções. Isso pesa muito sobre a questão do tempo livre. Não significa menos do que, mesmo onde o encantamento se atenua e as pessoas estão ao menos subjetivamente convictas de que agem por vontade própria, essa vontade é modelada por aquilo de que desejam estar livres fora do horário de trabalho. (Adorno, 1995, p. 71)

Segundo os profissionais da creche, a atuação das professoras e auxiliares nos momentos de parque consiste em "observar sem mediar muito", "deixar eles [as crianças] mais soltos", "observar eles brincarem". Ou, ainda: "0 momento é mais de observar". E observar, segundo revelam, implica: “atender”, “ajudar”, "resolver conflitos”, tal como se pode notar na cena abaixo:

São 14h43min No parque as professoras conversam sobre a "gravidez inesperada" de uma colega. [...] Do alto de um brinquedo, uma menina e um menino lançam areia e pedrinhas para baixo. A menina sobe e atira um pote plástico para escorregar e diz: "Nós tamo brincando. Eu jogo as coisinhas e faço ele pegar". No interior da casa de bonecas, quatro crianças gritam. Ao nos aproximarmos, uma delas avisa: "Ali tem monstro". Próxima à casinha, uma menina lança areia sobre a cabeça da colega que corre e é perseguida. A professora, de longe, intervém. [...] Uma garota enche um recipiente com areia e lança sobre um menino que brinca no gira-gira. Uma professora se aproxima: "Não é para ficar atirando areia". E sai. [...] Várias professoras conversam, formando um círculo. Duas crianças varrem e avisam a um menino que se aproxima também com uma vassoura: "Tu não vai limpar com a gente". 0 garoto olha fixamente para elas, afasta-se e guarda a vassoura. Uma criança chora. A auxiliar percebe e lhe diz: "Vai lá te lavar". [...] Noutro lado uma professora fala para uma menina (que se encontra "de castigo”): “Ô J., vai sentar”. Então se desloca pelo terreno do parque, chama as crianças e manda que sentem junto à porta da sala para que possam, em conjunto, se dirigir ao refeitório (para o momento de alimentação). Permanece uma turma no parque por mais alguns minutos. A auxiliar chama: "Vem, vamos lavar as mãos". Algumas crianças não atendem ao chamado e se dirigem ao alto de um brinquedo. A auxiliar se aproxima e, apontando o dedo para as crianças, diz em alto tom: “desce. Corre,

3. Inspiramo-nos aqui em Agamben (2004), fortemente alicerçado em Foucault (1999), quando escreve a respeito da biopolítica, de um poder sobre a vida ou de uma preocupação política na gestão da vida e na maximização da saúde das populações. 
vai lavar a mão. Já". Pega a vassoura e varre a área coberta, (enquanto as crianças lavam suas mãos, "cumprindo" o momento de higiene antes de seguirem para o refeitório.).

Em todas as dezessete entrevistas realizadas, as profissionais da creche afirmaram que os momentos de parque se referem a um período em que as crianças "se soltam". 0 local é também visto como um "espaço mais livre”, como se pode notar na fala de uma professora: "Na minha cabeça, eles, na sala, ficam meio dirigidos. Aí... não sei. Parece que eles vão pro parque... Sabe... Deixa eles". Conforme destacamos nas páginas introdutórias deste artigo, surge, nas vozes das professoras, uma espécie de contraposição entre "tempo de trabalho" e "tempo livre". Este último parece encontrar alguma justificação no discurso que faz uso da noção de "culturas infantis". Esta, grosso modo, diz respeito à perspectiva de que as crianças construiriam, na interação com seus pares, uma cultura que se distingue das formas adultas de interpretar o mundo, e que se expressam por meio da construção de significações autônomas e pela elaboração de processos de referenciação e significados próprios (Sarmento, 2004). Nesses termos, as crianças são consideradas como atores de pleno direito, e não como menores.

Quanto a esse aspecto, talvez pudéssemos dizer que a defesa da autonomia infantil não pode ser confundida com o papel daqueles materiais que não exigem a presença e/ou a intervenção mais cuidadosa de um adulto, promovendo um distanciamento entre as gerações, uma certa desobrigação dos maiores para com os pequenos. E, por outro lado, parece relacionar-se àquele comportamento recomendado, segundo Adorno (1995, p. 78), para o tempo livre: Do it your self, "faça você mesmo" um bom uso do tempo ganho. Para o autor, esse comportamento se inscreve num contexto mais amplo, por ele designado como "pseudoatividade", quando se torna preferível ao indivíduo incapaz de resistir entregar-se a satisfações compensatórias institucionalizadas do que se contrapor a exigências exteriores. Nesse contexto, poderíamos nos perguntar se a expressão "deixa eles”, fortalecida por discursos como o da "autonomia da infância”, representam não apenas uma certa isenção da autoridade adulta ou uma desobrigação - no sentido da negação - das relações entre adultos e crianças, mas também a nossa impossibilidade de pensar um tempo livre produtivo, uma vez que

[...] sob as condições vigentes, seria importuno e insensato esperar e exigir das pessoas que realizem algo de produtivo em seu tempo livre, uma vez que se destrói nelas justamente a produtividade, a capacidade criativa. (p. 77)

Para Adorno (1995), aquilo que as pessoas produzem no seu "tempo livre", que não necessariamente seria expressão da liberdade, não é melhor do que aquelas "atividades supérfluas" agrupadas sob o rótulo de hobby, uma vez que a capacidade para se relacionar de forma diferenciada com esse tempo lhes foi tolhida pelos mecanismos da indústria cultural. Nas suas palavras:

[...] quem quiser adaptar-se, deve renunciar cada vez mais à fantasia, em geral, mutilada por alguma experiência da primeira infância, nem consegue desenvolvê-la. A falta de fantasia, implantada e insistentemente recomendada pela sociedade, deixa as pessoas desamparadas em seu tempo livre. [...] Que efetivamente as pessoas só consigam fazer tão pouco de seu tempo livre se deve a que, de antemão, já lhes foi amputado o que poderia tornar prazeroso o tempo livre. (p. 76-77, grifo nosso)

Considerando as assertivas de Adorno (1995), poderíamos ponderar que também nos momentos de parque da creche se repetem as ações recomendadas para o tempo livre em geral: "matar" o tempo, ocupar-se com atividades e objetos padronizados, planejados "especialmente" para o nosso entretenimento, enfim, submeter-se à sociedade que dita o que deve ser no/do tempo livre, reforçando o domínio e a integração ao que está posto. 
Parece indiferente que essas crianças sejam levadas ao parque de um ambiente educacional ou a qualquer outro estabelecimento, uma vez que ali, naquele espaço, as relações educativas são eclipsadas, com exceção, por certo, de uma certa pedagogia do corpo. Este, perversamente, permanece confınado à supremacia dos espaços, dos olhares e das vozes que determinam onde, como e quando se movimentar; do que se desviar e também com que materiais se relacionar. Mas também é esse um corpo intimidado por meio de castigos, ameaças, premiações, que se estabelecem a partir da apreciação dos atos que se desviam das normas, infundindo temores, corrigindo, disciplinando comportamentos "inadequados". E, ainda, um corpo-pronunciado: investido por palavras, gestos e expressões faciais, que se colocam como mandatos, ordens enumeradas e/ou informações abreviadas, centralizadas no comportamento tido como adequado; informações que se caracterizam pela privação do diálogo ou, noutros termos, por uma linguagem predominantemente usada como instrumento de controle que se limita à informação, à restrição, à ordenação, à adesão à norma, raramente convergindo para a narrativa, para o pensamento a respeito das ações, enfim, para a revelação das particularidades.

\section{O olhar adulto no parque ou no tem- po livre}

0 dia está ensolarado, a temperatura amena. No parque, às 15:50, várias professoras conversam em círculo. Uma professora conversa com um grupo de crianças e amarra os tênis de um menino. [...] A professora circula de mãos dadas pelo parque com uma menina. [...] Escuta-se a voz de uma profissional ao longe: "Cuidado, tu vai cair". [...] Uma criança chora e é trazida para perto da professora, que diz: "Fizeram justiça, né? Sabe por quê? Porque ele viu que tu bateu nela”. [...] Uma menina passa engatinhando e comenta: "Sou um gato". [...] Uma professora chega ao parque e xinga uma criança que está "lavando" o quadro-verde:
"Para com isso! Quadro molhado? Como vai escrever depois?" Arranca o apagador da mão da criança e deposita-o sobre o quadro, longe de seu alcance. Minutos antes, a criança falava: "Vou deixar o quadro bem limpinho". [...] Uma profissional puxa duas crianças pelo braço e esbraveja. Cinco outras, reunidas em rodinha, conversam, enquanto duas permanecem paradas, de braços cruzados. [...] Uma criança, parada no canto do parque escuta: "Para de roer unha, menina!".

A atuação das professoras no parque revela-se basicamente em ações tais como amarrar calçados, retirar e dobrar casacos, auxiliar a subir em um brinquedo, circular pela área, algumas vezes acompanhadas e de mãos dadas com um ou dois pequenos. Além disso, pode-se observar, com frequência, dedos apontados em direção à criança, testas franzidas ou vozes altas, que exigem: "Para de roer unha..."; "guarda isso"; "vai lavar as mãos"; "cuidado, vais cair". São gestos e vozes distantes, talvez aliadas de um olhar asséptico que captura movimentos inconvenientes a fim de evitar feridas expostas, pois, como salienta uma profissional, ao final do dia, "o filho (a criança que frequenta a creche) tem que estar inteiro."

0 olhar das professoras circula, controla, tudo capta e assimila, mas pouco revela sobre as vozes singulares e sobre as experiências das crianças que habitam o espaço do parque: captura sinais de sede e oferece água; pede às crianças que coloquem casacos quando o frio vai chegando; sacode a poeira das calças; recolhe materiais não propícios; intercepta "desvios" e impede movimentos "perigosos", não convencionais.

Esse olhar talvez esteja em correspondência ${ }^{4}$ com exigências do mundo contemporâneo, que requer reações rápidas, percepções imediatas, sustentadas por técnicas adequadas que proporcionam ordem, alinhamento, previsibilidade.

4. Esse olhar encontra afinidade com a higiene, expressão prático-científica que concentra uma ação educativa na guarda e nos "cuidados" às crianças, sendo esses associados à ideia de uma sociedade moderna e civilizada e à ideologia do progresso (Costa, 1999; Kuhlmann Jr., 1998). 
Acaba-se por exigir, por um lado, maior semelhança a modelos predeterminados, civilizadamente deformados e, por outro, distanciam-se de percursos e atalhos que favorecem modos de aproximação não convencionais com os materiais presentes no parque.

Esse olhar asséptico, tecnificado, lembra aquela sensibilidade moderna -, descrita por Benjamin (2000) -, produzida pela "experiência do choque” (p. 111). Portador daquela, o indivíduo adapta-se e reage mecanicamente aos ritmos da máquina, das ruas, das massas, como estratégia de conservação. Movimentos idênticos, sempre iguais, são aguçados; a exigência de absorção rápida dos passantes, dos painéis de propaganda, dos sinais de trânsito e dos luminosos faz com que o sujeito se mantenha alerta diante de cada veloz, novo e repetido estímulo proveniente dos exteriores. Na busca por interceptar perigos de colisão ao movimentar-se pela cidade em meio à multidão (Benjamin, 2000), coloca-se a necessidade de total atenção ao instante e, ao mesmo tempo, à impossibilidade de observar, de relacionar-se com o tempo e o espaço de maneira qualitativamente diferente, de relacionar ações e criar novas associações, ou de perder-se em reflexões.

Se considerarmos essas ponderações no contexto da creche, pensando numa impossibilidade de olhar sem se desviar do que "convém", as crianças são, por um lado, poupadas dos perigos que ameaçam a conservação física, mas também levadas a realizar trajetos petrificados, que acabam por eclipsar a imaginação, a capacidade criadora, aquela mesma da qual nos fala Adorno (1995) e que é fundamental para o fruir do tempo verdadeiramente livre.

Por outro lado, ficam sujeitas à barbárie: expostas à violência ou submetidas à insegurança, devido à ausência de orientação e destituídas de qualquer mediação que não esteja relacionada à (auto)conservação física.

Arendt (2004) explica que

[...] toda criança procura instintivamente as autoridades para guiá-la nesse mundo em que ela ainda é uma estranha, em que não pode se orientar pelo próprio julgamento. À medida que os pais e os professores falham como autoridades, a criança se ajustará mais fortemente ao seu próprio grupo, e em certas condições o grupo de pares se tornará sua suprema autoridade. 0 resultado só pode ser o surgimento da turma e do bando. (p. 281)

A passividade do adulto diante das crianças constitui também uma forma de barbárie. Nesse caso, a responsabilidade se desloca, e os pequenos ficam não apenas sujeitos àquela "espontaneidade" - sugerida pelos professores como sinônimo de atividade criativa, imaginação, liberdade -, mas também permanecem subordinados a um conjunto de gestos e ações "espontâneos”, que englobam atitudes ligadas às satisfações imediatas dos impulsos submetidos a uma "vontade" incapaz de ser exercida livremente. Isso acaba se revelando em ações que diluem o outro em práticas autoritárias, a exemplo das crianças que arrancam os materiais que os "mais fracos" manipulam, ou daquelas que não permitem à outra que participe de um jogo. Tudo isso indica a exigência da proximidade de um olhar mais atento, da intervenção de um adulto que não pode transferir a autoridade à tirania do grupo. Para Momm (2006), recusar para si e transferir a responsabilidade aos pequenos, absolutizar o mundo da infância, representa uma aposta nesta "como única alternativa possível para as mazelas produzidas pela sociedade contemporânea (o) que, por sua vez, denuncia uma aposta que pode descambar para o irracionalismo" (p. 23). Nesse ínterim, percebe-se um deslocamento do governo da racionalidade para um universo liberto das convenções e dos imperativos da razão, para o mundo da "liberdade", da "espontaneidade", da "autonomia" da infância. A experiência da infância transforma-se em experimentação da infantilização.

É de se considerar a hipótese de que o adulto procura também se esquivar "da infância”, numa atitude fugidia, de esquecimento, ou, ainda, movido pelo esforço em não se deixar misturar ao universo lúdico, indeterminado, 
confuso, não soberano, que revela que tudo o que está aí, pode ser outra coisa (Gagnebin, 1997), tal como as crianças nos lembram quando sobem pelo escorregador por onde os dispositivos disciplinares mandam descer. Mas, na sociedade atual, as pessoas, em sua maioria, tornam-se "funcionários da tendência que se impõe” sobre elas (Adorno, 1995, p. 160), com dificuldades em transcender a norma. 0 que "se deseja” é não pensar, não realizar experiências intelectuais, mas antes voltar para casa depois de um dia de trabalho e, como nos disse uma professora: "sentar, ver televisão, ver filme, novela. Adoro! Esqueço do mundo porque a gente trabalha o dia inteiro...”.

\section{Palavras finais}

Na cena inicial descrita neste trabalho, vimos que as crianças são conduzidas, após ordenarem seus materiais, de um momento ao outro da rotina, atravessando um itinerário fixo e previsto. Nesse roteiro, os momentos vão se cumprindo ordenadamente, e a passagem de um período para o seguinte parece marcada pela ausência de uma linguagem capaz de reconstruir e recordar os tempos experienciados. Nesse contexto, a linguagem acerta o passo com a imagem do homem autômato, aquele que apara os choques: defende-se contra os infindos estímulos advindos do exterior e permanece atento apenas ao propósito de preservar-se mediante a execução de tarefas de forma eficiente. A linguagem resume-se em uma orientação que significa, sobremaneira, regulamentação corporal. Nessa perspectiva, ganham destaque os castigos e ameaças lançados sobre um corpo que acaba por se entregar aos ritmos impostos, aos espaços delimitados, aos movimentos sempre mais restritos e ajustados.

Atentar para o que as crianças fazem e traduzir o que fizeram é um movimento que dificilmente compõe os momentos de parque. A experiência dá lugar a práticas que apenas se repetem, cujos gestos simplificados e ações automatizadas colocam os pequenos sob sujeição de normas que provêm do exterior, o que nos faz lembrar as palavras de Horkheimer (2002):

O sujeito deve, por assim dizer, dedicar todas suas energias para estar "dentro e partir das coisas”, nos termos da definição pragmatista. [...] 0 ajustamento se torna o modelo para todos os tipos imagináveis de comportamento subjetivo. [...] [E o indivíduo] reage automaticamente, de acordo com padrões gerais de adaptação. (p. 100)

Quando as portas do parque se fecham para o almoço ou para o jantar, algumas professoras recolhem informações a respeito da limpeza dos corpos das crianças, enquanto outras recolhem brinquedos espalhados pelo parque. Por fim, recolhem as crianças, para que se dirijam ao banheiro e apaguem os rastros ${ }^{5}$ do tempo ali vivido. Nesses termos, os instantes passados no espaço do parque culminam em vivências imediatas, passageiras, ajustadas por detalhes assépticos. Mas esses rastros, de todo, não podem ser apagados, pois como salienta Vaz (2006),

[...] memória e história se recolocam também no corpo. Seja nos gestos miméticos que nos inscrevem numa tradição, seja nas marcas pessoais e intransferíveis que carregamos em nossos corpos. (p. 59)

No aforismo "Sobre a gênese da burrice", de Dialética do esclarecimento, Horkheimer e Adorno (1985) relacionam a delicadeza da vida intelectual em seu começo à sensibilidade das antenas do caracol - símbolo da inteligência:

Diante de cada perigo, a antena é recolhida e a cada nova ameaça aumentará a distância entre uma tentativa e outra: o corpo é paralisado pelo ferimento físico, o espírito pelo medo. Na origem, as duas coisas são insepa-

5. Esse processo implica o constrangimento daquilo que nos tornamos obrigados a ocultar e que, por não ser elaborado, ou antes, por ser mutilado pelo curso civilizador, retorna na forma de hostilidade, desse amor-ódio pelo corpo destacado por Horkheimer e Adorno (1985). 
ráveis. [...] Não apenas a pergunta proibida, mas a condenação da imitação, do choro, da brincadeira arriscada, pode provocar estas cicatrizes. (p. 240)

Como lembram os frankfurtianos, as relações entre adultos e crianças, e também entre as crianças e seus pares, se estabelecem, se revelam também por meio das marcas que se colocam sobre o corpo: produzem cicatrizes que podem ser compreendidas - quando se abre a possibilidade para lembrar as dores, os sofrimentos - no trabalho de rememoração; ou produzem o enrijecimento, a frieza, o esquecimento vazio, mas que não cessa de se manifestar nos atos de barbárie favorecidos nos momentos de parque quando convertidos em períodos de exposição à espontaneidade (mal orientada), à observação sem mediação, e à liberação do corpo para recomposição das forças para o momento seguinte, que coincidem com a idéia de tempo livre no mundo administrado.

\section{Referências bibliográficas}

ADORNO, T. W. Palavras e sinais: modelos críticos 2. Petrópolis: Vozes, 1995.

AGAMBEN, G. Homo Sacer. o poder soberano e vida nua. Belo Horizonte: UFMG, 2004.

ARENDT, H. Reflexões sobre Little Rock. In: Responsabilidade e julgamento. São Paulo: Companhia das Letras, 2004, p. 261-281.

BENJAMIN, W. Obras escolhidas l: magia, técnica, arte e política. 4. ed. São Paulo: Brasiliense, 1993.

Obras escolhidas III: Charles Baudelaire um lírico no auge do capitalismo. 4. ed. São Paulo: Brasiliense, 2000.

BRASIL. RCN - Referencial Curricular Nacional para educação infantil. Disponível em: <http: www.pmf.sc.gov.br/educa/infantil. htm>. Acesso em: 10 jul. 2008.

Ministério da Educação e do Desporto. Secretaria de Educação Fundamental. Coordenação Geral de Educação Infantil. Subsídios para credenciamento e funcionamento de instituições de educação infantil. Brasília, 1998.

COSTA, J. F. da. Ordem médica e norma familiar. 4. ed. Rio de Janeiro: Graal, 1999.

FOUCAULT, M. Em defesa da sociedade. São Paulo: Martins Fontes, 1999.

GAGNEBIN, J. M. Infância e pensamento. In: GHIRALDELLI Jr., P. (Org.). Infância, escola e modernidade. São Paulo: Cortez/Curitiba: UFPR, 1997, p. 83-100.

HORKHEIMER, M.; ADORNO, T. W. Dialética do esclarecimento: fragmentos filosóficos. Rio de Janeiro: Zahar, 1985.

HORKHEIMER, M. Eclipse da razão. São Paulo: Centauro, 2002.

KUHLMANN Jr., M. Infância e educação infantil: uma abordagem histórica. Porto Alegre: Mediação, 1998.

MOMM, C. M. Entre memória e história: estudos sobre a infância em Walter Benjamin. Florianópolis, 2006, 113 p. Dissertação (Mestrado em Educação)-Programa de Pós-Graduação em Educação da Universidade Federal de Santa Catarina, Santa Catarina. 2006.

RICHTER, A. C.; VAZ, A. F. Educação do corpo infantil como politização às avessas: um estudo sobre os momentos de alimentação em uma creche. In: REUNIÃO ANUAL DA ANPED, 30., 2007, Caxambu. Anais... Caxambu: ANPEd, 2007a, p. 1-14.

. Educar e cuidar do corpo: dispositivos biopolíticos de higienização em uma instituição de atendimento à pequena infância. In: CONGRESSO BRASILEIRO DE CIÊNCIAS DO ESPORTE e II CONGRESSO INTERNACIONAL DE CIÊNCIAS DO ESPORTe, 15., 2007, Recife. Anais... Recife: CBCE, 2007b, p. 1-10. 
SARMENTO, M. J. As culturas da infância nas encruzilhadas da segunda modernidade. In: CERISARA, A. B.; .SARMENTO, M. J. Crianças e miúdos: perspectivas sociopedagógicas da infância e educação. Porto: ASA, 2004, p. 9-31.

VAZ, A. F. Memória e progresso: sobre a presença do corpo na arqueologia da modernidade em Walter Benjamin. In: SOARES, C. L. (Org.). Corpo e história. 3. ed. Campinas: Autores Associados, 2006, p. 43-60.

. Escolarização, indústria cultural e processos de subjetivação contemporânea. In: COLÓQUIO INTERNACIONAL TEORIA CRÍTICA E EDUCAÇÃO, 2004, Piracicaba. Anais... Piracicaba, 2004, p. 1-10. CD-ROM.

Recebido em 21.09.09

Aprovado em 05.05.10

Ana Cristina Richter é mestre em Educação pela Universidade Federal de Santa Catarina (UFSC); doutoranda do Programa de Pós-graduação em Educação da UFPR; bolsista Capes; membro do Núcleo de Estudos e Pesquisas Educação e Sociedade Contemporânea (UFSC-UFPR/CNPq).

Alexandre Fernandez Vaz é doutor em Ciências Humanas e Sociais pela Leibnis Universität Hannover; professor dos Programas de Pós-graduação em Educação e Interdisciplinar em Ciências Humanas/UFSC; coordenador do Núcleo de Estudos e Pesquisas Educação e Sociedade Contemporânea (UFSC/CNPq); pesquisador CNPq. E-mail: alexfvaz@uol.com.br. 